\title{
PENGARUH GOOD CORPORATE GOVERNANCE TERHADAP KINERJA KEUANGAN PADA PERBANKAN SYARI'AH INDONESIA
}

\author{
Arry Eksandy \\ arry.eksandy@yahoo.com \\ Universitas Muhammadiyah Tangerang
}

\begin{abstract}
ABSTRAK
Penelitian ini bertujuan untuk membuktikan secara empiris pengaruh good corporate governance terhadap kinerja keuangan perbankan syariah. Variabel dependen dalam penelitian ini adalah kinerja keuangan yang diukur dengan Return On Asset (ROA). Variabel independen dalam penelitian ini adalah Good Corporate Governance (GCG) yang diukur dengan dewan direksi, dewan komisaris independen, dewan pengawas syariah dan komite audit.Populasi pada penelitian ini adalah Bank Umum Syariah (BUS) yang terdaftar di Bank Indonesia sebanyak 11 bank. Berdasarkan metode purposive sampling, sampel yang diperoleh sebanyak 8 bank syari'ah yang memenuhi kriteria. Data penelitian diperoleh dari annual report selama periode 2011-2014. Metode analisis yang digunakan adalah analisis regresi data panel dengan software Eviews for windows versi 9.0.Hasil penelitian menunjukkan bahwa dewan direksi berpengaruh terhadap kinerja keuangan, sedangkan komisaris independen, dewan pengawas syariah dan komite audit tidak berpengaruh terhadap kinerja keuangan. Secara bersama-sama dewan direksi, komisaris independen, dewan pengawas syari'ah dan komite audit berpengaruh terhadap ROA.
\end{abstract}

\section{Kata Kunci: Kinerja Keuangan, Good Corporate Governance}

\section{PENDAHULUAN}

Krisis ekonomi global yang terjadi beberapa waktu yang lalu memberikan dampak yang tidak baik terhadap kinerja keuangan perusahaan hingga saat ini. Salah satu faktor penyebab terjadinya krisis keuangan perusahaan karena lemahnya implementasi sistem tata kelola perusahaan atau Corporate Governance. (The World Bank, 1998, dalam Oktapiyani, 2009). Akan tetapi hal ini tidak berpengaruh terhadap Bank syariah, hal ini dikarenakan Bank Syariah tidak dibebani kewajiban untuk membayar bunga simpanan kepada para nasabahnya. Bank Syariah hanya membayar bagi hasil kepada nasabahnya sesuai dengan margin keuntungan yang diperoleh bank dari hasil investasi yang dilakukannya. Dengan sistem ini bank syariah tidak mengalami negative spread sebagaimana dialami oleh perbankan konvensional yang memakai sistem bunga. Ini dibuktikan oleh Bank Muamalat Indonesia (pada waktu itu merupakan satu-satunya bank yang beroperasi dengan sistem syariah) yang tidak terpengaruh dengan kondisi perekonomian. Lemahnya penerapan Corporate Governance inilah yang menjadi pemicu utama terjadinya berbagai skandal keuangan pada bisnis perusahaan. Kasus penipuan, penggelapan, pembobolan dan korupsi yang dilakukan oleh oknum bank itu sendiri banyak terjadi di perbankan Indonesia. Banyak perusahaan bangkrut yang diindikasikan sebagai akibat belum menerapkan Prinsip-prinsip Good Corporate Governance. disamping banyaknya praktik Korupsi, Kolusi, dan Nepotisme (KKN) (Joni Emirzon, 2006).

Jumlah dewan direksi dalam perusahaan yang tidak sesuai dengan aturan PBI atau tidak menjalani proses self assessment akan menurunkan suatu bentuk pengawasan terhadap kinerja keuangan yang baik dan terkontrol. Proporsi dewan komisaris independen yang tidak terafiliasi dengan direksi atau tidak memiliki hubungan keluarga maupun keuangan dalam kepemilikan saham dapat mempengaruhi kemampuanya untuk bertindak independen. Dewan 
pengawas syariah senantiasa mengikuti aturan dan prinsip syariah dengan jumlah anggota yang telah ditetapkan DPS pada peraturan Bank Indonesia. Kepemilikan institusional dapat berpengaruh dalam pemanfaatan aktiva perusahaan dan sebagai pencegahan terhadap pemborosan yang dilakukan manajemen. Kurangnya pengawasan atas aktivitas manajemen oleh dewan komisaris mengakibatkan penurunan kerja yang kurang efektif. Kurangnya jumlah komite audit dapat menimbulkan fraud di perusahaan. Audit extern dilaksanakan berdasarkan standar auditing yang ditetapkan Ikatan Akuntan Indonesia. Standard tersebut mengharuskan auditor merencanakan dan melaksanakan audit agar memperoleh keyakinan memadai bahwa laporan keuangan bebas dari salah saji yang material.

\section{TINJAUAN PUSTAKA}

\section{Teori Keagenan (Agency Theory)}

Konsep agency theory didasari pada permasalahan agensi yang muncul ketika pengurusan suatu perusahaan terpisah dari kepemilikannya (Nuswandari, 2009). Agency theory menurut oleh Jensen dan Meckling (1976) memandang bahwa manajemen perusahaan sebagai agen bagi para pemegang saham, akan bertindak dengan penuh kesadaran bagi kepentingannya sendiri, bukan sebagai pihak yang arif dan bijaksana serta adil terhadap pemegang saham. Dengan kata lain, agency theory memandang bahwa pihak manajemen tidak dapat dipercaya untuk bertindak sebaik-baiknya bagi kepentingan publik pada umumnya maupun shareholders pada khususnya.

\section{Dewan Direksi}

Menurut Peraturan Bank Indonesia nomor 11/33/PBI/2009, dewan direksi adalah organ perseroan yang berwenang dan bertanggung jawab penuh atas pengurusan perseroan untuk kepentingan perseroan sesuai dengan maksud dan tujuan perseroan serta mewakili perseroan, baik di dalam dan di luar pengadilan sesuai dengan ketentuan anggaran dasar sebagaimana dimaksud dalam Undang-Undang No. 40 Tahun 2007 tentang Perseroan Terbatas. Jumlah anggota dewan direksi paling kurang 3 (tiga) orang dan kriteria untuk menjadi seorang direksi tunduk pada peraturan Bank Indonesia. Pengangkatan dan penggantian direksi dalam RUPS haruslah memperhatikan rekomendasi dari komite remunerasi dan nominasi.

\section{Dewan Komisaris Independen}

Menurut peraturan Bank Indonesia nomor 11/33/PBI/2009 komisaris independen adalah anggota dewan komisaris yang tidak memiliki hubungan keuangan, kepengurusan, kepemilikan saham dan atau hubungan keluarga dengan pemegang saham pengendali, anggota dewan komisaris dan/atau anggota direksi. Jumlah komisaris independen paling kuranng lima puluh persen dari jumlah anggota komisaris adalah komisaris independen. Komsaris independen juga tidak boleh memiliki hubungan keuangan atau hubungan kepemilikan saham dengan bank sehingga dapat mendukung kemampuannya untuk bersikap independen. Tugas dari komisaris independen adalah untuk membantu dewan komisaris dalam menjalankan tugasnya agar lebih efektif.

\section{Dewan Pengawas Syariah}

Menurut peraturan Bank Indonesia nomor 11/33/PBI/2009 dewan pengawas syariah (DPS) adalah dewan yang bertugas memberikan nasehat dan saran kepada direksi serta mengawasi kegiatan bank agar sesuai dengan Prinsip Syariah. Ketentuan mengenai jumlah anggota dan kriteria untuk menjadi anggota DPS tunduk pada peraturan Bank Indonesia. Anggota DPS diangkat melalui RUPS. 


\section{Komite Audit}

Menurut Keputusan Menteri nomor 117 Tahun 2002, tujuan dibentuknya komite audit adalah membantu komisaris atau dewan pengawas dalam memastikan efektifitas pelaksanaan tugas auditor eksternal dan auditor internal. Badan Pengawas Pasar Modal (BAPEPAM) dalam surat edarannya tahun 2003 mengatakan bahwa tujuan komite audit adalah membantu dewan komisaris.

\section{Perumusan Hipotesis}

$\mathrm{H}_{1}$ : Dewan Direksi berpengaruh positif terhadap kinerja perusahaan perbankan syariah.

$\mathrm{H}_{2}$ : Proporsi Dewan Komisaris Independen berpengaruh positif terhadap kinerja perusahaan perbankan syariah.

$\mathrm{H}_{3}$ : Dewan Pengawas Syariah berpengaruh positif terhadap kinerja perusahaan perbankan syariah.

$\mathrm{H}_{4}$ : Komite Audit berpengaruh positif terhadap kinerja perusahaan perbankaan syariah.

\section{METODE PENELITIAN}

\section{Populasi dan Sampel}

Populasi yang digunakan dalam penelitian ini adalah Bank Umum Syari'ah Indonesia periode 2011-2014 dengan jumlah 11 bank syariah. Dengan metode purposive sampling diperoleh 8 bank syari'ah dan jumlah data 32 observasi yang selanjutnya digunakan sebagai sumber data untuk dianalisis.

\section{Definisi dan Operasional Variabel Variabel Independen}

Variabel independen dalam penelitian ini adalah good corporate governance, dewan direksi, dewan komisaris independent, dewan pengawas syariah dan komite audit.

\section{1) Jumlah Dewan Direksi}

Jumlah anggota dewan direksi masing-masing bank pada periode $t$ dibagi dengan Logaritma Natural (Ln) dari total asset pada periode t. (Hamid, 2014).

\section{2) Proporsi Komisaris Indpenden}

Proporsi komisaris independen yang ada dalam dewan komisaris pada periode $t$ atau jumlah komisaris independen dibagi dengan jumlah komisaris secara keseluruhan pada peiode $\mathrm{t}$. (Hamid, 2014).

3)

\section{Jumlah Dewan Pengawas Syariah}

Jumlah anggota DPS telah memenuhi ketentuan apabila sesuai Peraturan Bank Indonesia Nomor 11/3/PBI/2009 tanggal 29 Januari 2009 yang menetapkan bahwa anggota DPS sekurang-sekurangnya sebanyak 2 (dua) orang dan maksimal sebanyak 50\% dari jumlah Direksi.

\section{4) Komite Audit}

Menurut PBI Nomor 8/4PBI/2006 Komisaris Independen dan Pihak Independen yang menjadi anggota Komite Audit sebagaimana dimaksud pada ayat (1) paling kurang 51\% (lima puluh satu perseratus) dari jumlah anggota Komite Audit.

\section{b. Variabel dependen}

Dalam penelitian ini yang menjadi variabel terikat atau dependen adalah kinerja keuangan bank syariah yang diukur dengan Return On Asset (ROA). Menurut Brigham dan Ehrhadrt (2005) dalam Praptiningsih (2009) ROA adalah rasio laba sebelum bunga dan pajak (EBIT) 
atau laba bersih dibagi dengan nilai buku aset di awal tahun fiskal. Return on Asset mengukur laba perusahaan yang berhubungan dengan semua sumber daya disposal (modal pemegang saham ditambah dana jangka pendek dan panjang yang dipinjam).

\section{Teknik Analisis Data}

Dalam penelitian ini, teknik analisis data yang digunakan adalah analisis regresi data panel dengan bantuan sofware pengolah data statistik yaitu Eviews 9.0. Model regresi data panel dapat ditulis sebagai berikut (Winarno, 2015: 4.1):

$Y_{i t}=\beta_{0}+\beta_{1} X 1_{i t}+\beta_{2} X 2_{i t}+\beta_{3} X 3_{i t}+\beta_{4} X 4_{i t}+e_{i t}$

Keterangan:

$$
\begin{aligned}
& Y \quad=\text { Kinerja Keuangan } \\
& \beta \quad=\text { Konstanta } \\
& X 1=\text { Dewan Direksi } \\
& X 2=\text { Dewan Komisaris Independen } \\
& X 3=\text { Dewan Pengawas Syariah } \\
& X 4=\text { Komite Audit } \\
& i \quad=\text { Sampel } \\
& i \quad=\text { Tahun } \\
& e \quad=\text { Komponen eror }
\end{aligned}
$$

HASIL PENELITIAN DAN PEMBAHASAN

\section{Statistik Deskriptif}

\begin{tabular}{|lccccc|}
\multicolumn{7}{c|}{ Statistik Deskriptif } \\
Mean & ROA & DD & KI & DPS & KA \\
Median & 1.255000 & 4.343750 & 2.468750 & 2.343750 & 4.250000 \\
Maximum & 1.230000 & 4.000000 & 2.000000 & 2.000000 & 4.000000 \\
Minimum & 3.810000 & 6.000000 & 4.000000 & 3.000000 & 6.000000 \\
Std. Dev. & 0.080000 & 3.000000 & 1.000000 & 2.000000 & 2.000000 \\
Skewness & 0.865228 & 0.937029 & 0.621360 & 0.482559 & 1.270001 \\
Kurtosis & 1.012312 & 0.224309 & 0.119272 & 0.657952 & -0.192000 \\
& 4.219999 & 2.225006 & 2.689315 & 1.432900 & 1.960000 \\
Jarque-Bera & 7.450000 & 1.069165 & 0.204571 & 5.583204 & 1.638741 \\
Probability & 0.024113 & 0.585914 & 0.902772 & 0.061323 & 0.440709 \\
& & & & & \\
Sum & 40.16000 & 139.0000 & 79.00000 & 75.00000 & 136.0000 \\
Sum Sq. Dev. & 23.20720 & 27.21875 & 11.96875 & 7.218750 & 50.00000 \\
Observations & & & & & \\
\hline
\end{tabular}

Sumber: Output Eviews 9.0, 2016 


\section{Pemilihan Model Regresi Data Panel}

Uji Chow Test (Common Effect vs Fixed Effect)

\begin{tabular}{|c|c|c|c|}
\hline $\begin{array}{l}\text { Redundant Fixed Effects } \\
\text { Equation: FE } \\
\text { Test cross-section fixed e }\end{array}$ & & & \\
\hline Effects Test & Statistic & d.f. & Prob. \\
\hline Cross-section F & 2.527337 & $(7,20)$ & 0.0491 \\
\hline Cross-section Chi-square & 20.278352 & 7 & 0.0050 \\
\hline
\end{tabular}

Sumber: Output Eviews 9.0, 2016

Uji Langrage Multiplier (Common Effect vs Random Effect)

Lagrange Multiplier Tests for Random Effects

Null hypotheses: No effects

Alternative hypotheses: Two-sided (Breusch-Pagan) and one-sided (all others) alternatives

\begin{tabular}{|c|c|c|c|}
\hline & \multicolumn{3}{|c|}{ Test Hypothesis } \\
\hline & Cross-section & Time & Both \\
\hline Breusch-Pagan & $\begin{array}{l}0.096676 \\
(0.7559)\end{array}$ & $\begin{array}{l}2.208242 \\
(0.1373)\end{array}$ & $\begin{array}{l}2.304918 \\
(0.1290)\end{array}$ \\
\hline
\end{tabular}

\section{Uji Hausman (fixed effect vs Random Effect)}

Correlated Random Effects - Hausman Test

Equation: RE

Test cross-section random effects

\begin{tabular}{|llrr|}
\hline \hline Test Summary & $\begin{array}{l}\text { Chi-Sq. } \\
\text { Statistic Chi-Sq. d.f. }\end{array}$ & Prob. \\
\hline \hline Cross-section random & 7.193743 & 4 & 0.1260 \\
\hline \hline
\end{tabular}

Sumber: Output Eviews 9.0, 2016

Tabel 5. Kesimpulan Model

\begin{tabular}{|c|l|l|l|}
\hline $\begin{array}{c}\text { N } \\
\mathbf{0}\end{array}$ & \multicolumn{1}{|c|}{ Metode } & \multicolumn{1}{|c|}{ Pengujian } & \multicolumn{1}{|c|}{ Hasil } \\
\hline 1 & Chow-Test & $\begin{array}{l}\text { Common Effect vs } \\
\text { Fixed Effect }\end{array}$ & $\begin{array}{l}\text { Fixed } \\
\text { Effect }\end{array}$ \\
\hline 2 & $\begin{array}{l}\text { Lagrange Multiplier } \\
\text { (LM-Test })\end{array}$ & $\begin{array}{l}\text { Common Effect vs } \\
\text { Random Effect }\end{array}$ & $\begin{array}{l}\text { Common } \\
\text { Effect }\end{array}$ \\
\hline 3 & Hausman Test & $\begin{array}{l}\text { Fixed Effect vs } \\
\text { Random Effect }\end{array}$ & $\begin{array}{l}\text { Fixed } \\
\text { Effect }\end{array}$ \\
\hline
\end{tabular}

Dengan demikian model regresi data panel yang akan dianalisi lebih lanjut dalam penelitian ini adalah Fixed Effect Model. 


\section{Pengujian Hipotesis}

\section{Uji t}

Uji t dilakukan untuk menunjukkan seberapa signifikan pengaruh variabel independen secara individual terhadap variabel dependen. Dengan dilihat dari nilai t tabel menggunakan tingkat signifikan a adalah 0,05dan degree of freedom $=\mathrm{n}-\mathrm{k}$ atau $\mathrm{df}=32-5=27$ ( $\mathrm{n}$ adalah banyaknya observasi dalam kurun waktu data dan $\mathrm{k}$ adalah banyaknya variabel bebas dan terikat) maka diproleh nilai t tabel sebesar 2.05183. Hasil pengujian dapat dilihat pada tabel berikut:

\section{Uji t}

Dependent Variable: ROA

Method: Panel Least Squares

Date: 10/18/16 Time: $18: 12$

Sample: 20112014

Periods included: 4

Cross-sections included: 8

Total panel (balanced) observations: 32

\begin{tabular}{|crrrr|}
\hline \hline Variable & Coefficient & Std. Error & t-Statistic & Prob. \\
\hline \hline C & -5.282525 & 3.257562 & -1.621619 & 0.1205 \\
DD & 1.092377 & 0.349711 & 3.123652 & 0.0053 \\
KI & 0.293086 & 0.416532 & 0.703633 & 0.4898 \\
DPS & 0.212430 & 0.835544 & 0.254242 & 0.8019 \\
KA & 0.134371 & 0.209929 & 0.640078 & 0.5294 \\
\hline \hline
\end{tabular}

Sumber: Output Eviews 9.0, 2016

\section{Uji F}

Uji F digunakan untuk menguji apakah semua variabel independen dalam model regresi secara bersama-sama berpengaruh terhadap variabel dependen. Hasil pengujian dapat dilihat pada tabel berikut:

\section{Uji F}

Dependent Variable: ROA

Method: Panel Least Squares

Date: 10/18/16 Time: 18:12

Sample: 20112014

Periods included: 4

Cross-sections included: 8

Total panel (balanced) observations: 32

Cross-section fixed (dummy variables)

\begin{tabular}{|lrll|}
\hline \hline R-squared & 0.611154 & Mean dependent var & 1.255000 \\
Adjusted R-squared & 0.397289 & S.D. dependent var & 0.865228 \\
S.E. of regression & 0.671715 & Akaike info criterion & 2.322032 \\
Sum squared resid & 9.024028 & Schwarz criterion & 2.871683 \\
Log likelihood & -25.15251 & Hannan-Quinn criter. & 2.504226 \\
F-statistic & 2.857658 & Durbin-Watson stat & 2.385299 \\
Prob(F-statistic) & 0.019979 & & \\
\hline
\end{tabular}

Sumber: Output Eviews 9.0, 2016 


\section{Koefisien Determinasi $\left(\mathbf{R}^{2}\right)$}

Uji koefisien determinasi digunakan untuk melihat seberapa besar pengaruh variabel independen, yaitu dewan direksi, komisaris independen, dewan pengawas syariah dan komite audit terhadap variabel dependen, yaitu kinerja keuangan yang diukur dengan ROA.

\section{Koefisien Determinasi}

\begin{tabular}{|c|c|c|c|}
\hline \multicolumn{4}{|c|}{$\begin{array}{l}\text { Dependent Variable: ROA } \\
\text { Method: Panel Least Squares } \\
\text { Date: } 10 / 18 / 16 \text { Time: } 18: 12 \\
\text { Sample: } 20112014 \\
\text { Periods included: } 4 \\
\text { Cross-sections included: } 8 \\
\text { Total panel (balanced) observations: } 32\end{array}$} \\
\hline \multicolumn{4}{|c|}{ Cross-section fixed (dummy variables) } \\
\hline $\begin{array}{l}\text { R-squared } \\
\text { Adjusted R-squared } \\
\text { S.E. of regression } \\
\text { Sum squared resid } \\
\text { Log likelihood } \\
\text { F-statistic } \\
\text { Prob(F-statistic) }\end{array}$ & $\begin{array}{r}0.611154 \\
0.397289 \\
0.671715 \\
9.024028 \\
-25.15251 \\
2.857658 \\
0.019979\end{array}$ & $\begin{array}{l}\text { Mean dependent var } \\
\text { S.D. dependent var } \\
\text { Akaike info criterion } \\
\text { Schwarz criterion } \\
\text { Hannan-Quinn criter. } \\
\text { Durbin-Watson stat }\end{array}$ & $\begin{array}{l}1.255000 \\
0.865228 \\
2.322032 \\
2.871683 \\
2.504226 \\
2.385299\end{array}$ \\
\hline
\end{tabular}

Sumber: Output Eviews 9.0, 2016

\section{Analisis Regresi Data Panel}

Penelitian dengan regresi data panel ini digunakan untuk melihat pengaruh antara variabel independen terhadap variabel dependen. Hasil analisis regresi data panel pada model fixed effect menunjukkan hasil variabel dewan direksi berpengaruh positif terhadap kinerja keuangan (ROA), komisaris independen, dewan pengawas syariah dan komite audit tidak berpengaruh terhadap kinerja keuangan (ROA). Persamaan regresi didapatkan sebagai berikut:

$$
\text { ROA = -5.282525 + 1.092377 DD + 0.293086 KI + 0.212430 DPS +0.134371 }
$$

\section{PEMBAHASAN}

\section{Pengujian Hipotesis Pertama $\left(\mathrm{H}_{1}\right)$}

Hipotesis pertama yang diajukan pada penelitian ini adalah dewan direksi yang memiliki $\mathrm{t}$ hitung $<\mathrm{t}$ tabel $(3.123652>2.05183)$ dengan nilai signifikansi sebesar $0.0053<$ taraf signifikansi 0,05. Hasil tersebut menunjukkan bahwa dewan direksi berpengaruh positif terhadap kinerja keuangan (ROA). Hal ini didukung oleh pendapat Alexander, Fernell, Halporn (1993) dan Goodstein, Gautarn, Boeker (1994) dalam Wardhani (2006) yang menyatakan jumlah dewan yang besar menguntungkan perusahaan dari sudut pandang resource dependence yaitu bahwa perusahaan tergantung dengan dewannya untuk dapat mengelola sumber dayanya secara lebih baik. 


\section{Pengujian Hipotesis Kedua $\left(\mathbf{H}_{2}\right)$}

Hipotesis kedua yang diajukan pada penelitian ini adalah komisaris independen yang memiliki t hitung > t tabel $(0.703633<2.05183)$ dengan nilai signifikansi sebesar $0.4898>$ taraf signifikansi 0,05. Hasil tersebut menunjukkan bahwa komisaris independen tidak berpengaruh terhadap kinerja keuangan (ROA). Hasil penelitian ini sejalan dengan Erfina (2014). Komisaris independen adalah anggota dewan komisaris yang bukan merupakan pegawai atau orang yang berurusan langsung dengan perusahaan tersebut, dan tidak mewakili pemegang saham. Komisaris independen diangkat karena pengalamannya dianggap berguna bagi perusahaan tersebut. Mereka dapat mengawasi dewan komisaris dan mengawasi bagaimana perusahaan tersebut dijalankan.

\section{Pengujian Hipotesis Ketiga $\left(\mathrm{H}_{3}\right)$}

Hipotesis ketiga yang diajukan pada penelitian ini adalah dewan pengawas syariah yang memilikit $\mathrm{t}$ hitung $<\mathrm{t}$ tabel $(0.254242<2.05183)$ dengan nilai signifikansi sebesar $0.8019>$ taraf signifikansi 0,05. Hasil tersebut menunjukkan bahwa dewan pengawas syariah tidak berpengaruh terhadap kinerja keuangan (ROA). Pada kenyataanya DPS tidak berpengaruh terhadap kinerja perbankan hal ini karena DPS yang ada di dalam sebuah bank mempunyai rangkap jabatan sebagai DPS juga di bank lain yang mengakibatkan kurang baiknya/ kurang fokusnya kinerja seorang DPS tersebut dalam mengawasi sebuah bank. Sehingga kinerja DPS dianggap kurang baik dan tidak mempengaruhi kinerja perbankan.

\section{Pengujian Hipotesis Keempat $\left(\mathbf{H}_{4}\right)$}

Hipotesis keempat yang diajukan pada penelitian ini adalah komite audit yang mempunyai $\mathrm{t}$ hitung $<\mathrm{t}$ tabel $(0.640078<2.05183)$ dengan nilai signifikansi sebesar $0.5294>$ taraf signifikansi 0,05. Hasil tersebut menunjukkan bahwa komite audit tidak berpengaruh terhadap kinerja keuangan (ROA). Hasil penelitian ini menunjukan bahwa komite audit tidak berengaruh terhadap kinerja keuangan perbankan syariah dikarenakan kinerja yang kurang efektif karena rangkap jabatan yang dimiliki komite audit yang berdampak kurangnya pengawasan atas aktivitas manajemen, serta kurangnya intensif eksternal untuk mendorong terciptanya efisiensi di perusahaan melalui persaingan yang fair.

\section{KESIMPULAN}

Berdasarkan hasil analisis data dan pembahasan yang telah diuraikan, maka dapat ditarik kesimpulan sebagai berikut : Dari semua variabel independen (dewan direksi, komisaris independen, dewan pengawas syariah dan komite audit dalam good corporate governance) yang diduga berpengaruh terhadap kinerja keuangan, hanya variabel dewan direksi yang berpengaruh positif terhadap kinerja keuangan perbankan syariah. Dari hasil uji t dengan melihat nilai signifikansi, variabel komisaris independen, dewan pengawas syariah dan komite audit memiliki nilai yang tidak signifikan dan tidak mempengaruhi kinerja keuangan perbankan syariah dengan nilai t masing-masing sebesar $0.4898,0.8019$ dan 0.5294 . Sedangkan variabel dewan direksi berpengaruh positif terhadap kinerja keuangan perbankan syariah dengan nilai signifikansi t sebesar 0.0053. Dari hasil uji $\mathrm{F}$, terbukti bahwa nilai signikansi $\mathrm{F}$ lebih besar dari nilai signifikansi yang telah ditentukan sebelumnya, yaitu 0,05. Artinya seluruh variabel independen dalam penelitian ini secara bersama-sama (simultan) berpengaruh tetapi tidak signifikan terhadap kinerja keuangan perbankan syariah sebagai variabel dependen. Hasil uji koefisien determinasi, menunjukan nilai Adjusted R-squared pada model regresi adalah 0,397289 yang menunjukan kemampuan variabel independen (dewan direksi, komisaris independen, dewan pengawas syariah dan komite audit) dalam menjelaskan variabel dependen kinerja keuangan (ROA) adalah sebesar 39,72\% sedangkan sisanya sebesar $60,28 \%$ dijelaskan variabel lain yang tidak termasuk dalam penelitian ini. 


\section{DAFTAR PUSTAKA}

Adayani, W. dan Purwant, L. 2006. Pengaruh Good Corporate Governance Terhadap Kinerja Perusahaan Pada Perusahaan Textile Mill Product dan Apparel And Other Textile Product Yang Terdaftar di BEJ. Jurnal Manajemen, Akuntansi dan Bisnis Vol. 5, No. 1. Hal: 1-7.

Al-Qur'an dan Terjemahannya. Departemen Agama RI. 2011. AN-Nisa Ayat 29. Penerbit Mekar Surabaya.

Al-Qur'an dan Terjemahannya. Departemen Agama RI. 2011. AL-Anfal Ayat 27. Penerbit Mekar Surabaya.

Chapra, M. Umer dan Ahmed H. 2008. Corporate Governance Lembaga Keuangan Syariah. Jakarta: Bumi Aksara.

Efferin, Sujoko (et.al). 2012. Metode Penelitian Akuntansi; Mengungkap Fenomena dengan Pendekatan Kuantitatif dan Kualitatif. Yogyakarta : Graha Ilmu.

Eksandy, A. (2017). Pengaruh Ukuran Perushaan, Solvabilitas, Profitabilitas Dan Komite Audit Terhadap Audit Delay (Pada Perusahaan Properti dan Real Estate yang Terdaftar di Bursa Efek Indonesia Pada Tahun 2012-2015). Competitive Jurnal Akuntansi dan Keuangan, 1(2).

FCGI. 2001. Corporate Governance: Tata Kelola Perusahaan. Edisi Ketiga, Jakarta.

Ghyad, Racha. 2008. Corporate Governance and The Global Performance of Islamic Banks. Journal Humanomic Vol. 24, No. 3. Pp: 207-208.

Hastuti, Theresia Dwi. 2005. Hubungan Antara Good Corporate dan Struktur Kepemilikan Dengan Kinerja Keuangan (Studi Kasus Pada Perusahaan yang Listing di BEJ). SNA VII Solo. Hal: 238-247.

Jensen, M. and Meckling, W. 1976. Theory of the firm: managerial behavior, agency Costs and oenership structure. Journal of Financal Economic, Vol. 3, pp. 305-60.

Kamal, Miko. (2011). Konsep Corporate Governance di Indonesia, Jurnal Manajemen Teknologi Vol 10 No. 2, 2011.

Macey, J., and M. O'Hara., 2003, The Corporate Governance of Banks, Federal Reserve Bank of New York Economic Policy. Review 9, No. 1 (April): 91-107.

Neuman, W.Lawrence. 2013. Metodologi Penelitian Sosial: Pendekatan Kualitatif dan Kuantitatif. Edisi.7. Penerjemah: Edina T. Sofia. Jakarta: PT.Indeks.

Nuswandari, Cahyani, 2009, Pengaruh Corporate Governance Perception Index Terhadap Kinerja Perusahaan pada Perusahaan yang Terdaftar di Bursa Efek Jakarta. Jurnal Bisnis dan Ekonomi, Vol. 16, No. 2. Hal: 70-84.

Peraturan Bank Indonesia (PBI) No. 9 Tahun 2007 Tentang Sistem Penilaian Tingkat Kesehatan Bank Umum Berdasarkan Prinsip Syariah.

Peraturan Bank Indonesia (PBI) No. 8/4/PBI/2006 Tentang Pelaksanaan GCG bagi Bank Umum.

Peraturan Bank Indonesia (PBI) No. 11/33/PBI/2009 Tentang Pelaksanaan PrinsipPrinsip GCG bagi Bank Umum Syariah.

Sayidah, Nur. (2007). Pengaruh Kualitas Corporate Governance terhadap Kinerja Perusahaan Publik (Studi Kasus Peringkat 10 Besar CGPI Tahun 2003, 2004, 2005). JAAI, Vol. 11, No.1. Hal: 1-19.

Sugiyono. 2014. Metode Penelitian Kuantitatif, Kualitatif Dan R\&D. Bandung : Alfabeta.

Sunandar, Heri. 2005. Peran dan Fungsi Dewan Pengawas Syariah (Shari'a Supervisory Board) Dalam Perbankan Syariah di Indonesia. Hukum Islam. Vol. IV No. 2. Hal: 159-172. 
Winarno, Wahyu, Wing. 2015. Aplikasi Analisis Ekonometrika dan Statistika Dengan Eviews 9.0. Yogyakarta: Badan Penerbit UPP STIM YKPN.

Wardhani, Ratna . 2006. Mekanisme Corporate Governance Dalam Perusahaan yang Mengalami Permasalahan Keuangan (Financially Distressed Firms). Simposium Nasional Akuntansi 9 Padang. Hal: 1-26. 